\title{
Vindication of Professional Reputation Arising from Defamatory Online Publications
}

\author{
Ian Freckelton Q. C.1,2,3,4 (1) \\ ${ }^{1}$ Crockett Chambers, Melbourne, Australia \\ ${ }^{2}$ Supreme Court of the Republic of Nauru, Nauru \\ ${ }^{3}$ Fellow of Law and Psychiatry, University of Melbourne, Melbourne, Australia \\ ${ }^{4}$ Johns Hopkins University, Washington, DC, USA \\ Email: i.freckelton@vicbar.com.au
}

How to cite this paper: Ian Freckelton, Q. C. (2020). Vindication of Professional Reputation Arising from Defamatory Online Publications. Beijing Law Review, 11, 382-397. https://doi.org/10.4236/blr.2020.111024

Received: February 20, 2020

Accepted: March 28, 2020

Published: March 31, 2020

Copyright (c) 2020 by author(s) and Scientific Research Publishing Inc. This work is licensed under the Creative Commons Attribution International License (CC BY 4.0).

http://creativecommons.org/licenses/by/4.0/ (c) (i) Open Access

\begin{abstract}
This article identifies the growing phenomenon of professionals suing their clients/patients for online defamation of their professional status and reputation. It reviews the phenomenon of ratings websites and scrutinises the growing popularity of such forms of feedback, identifying benefits but also detriments of such sites, especially when they are commercially influenced or unregulated. It notes that adverse feedback can be legitimate and helpful for both consumers and professionals but that it can also be the product of distress, anger and malice. This article reviews key court decisions in Germany, England, Canada and Australia where actions by disgruntled practitioners against clients/patients and/or publishing websites have succeeded in spite of the traditional diffidence on the part of professionals to engage in such litigation. It argues that the phenomena of defamation actions taken by professionals against their clients/patients and attempts to secure injunctive relief to prevent ongoing publication of false and reputation-damaging material are likely to grow in light of the potential for disinhibited and damaging publications by aggrieved persons on social media and other online forums.
\end{abstract}

\section{Keywords}

Defamation, Applications for Injunctions, Litigation against Clients/Patients, Non-Maleficence, Damage to Reputation

\section{Introduction}

An aspect of the evolving online environment is that there are now multiple ways in which members of the public can express their views about the calibre of professionals who provide them with services and about the quality of the ser- 
vices that have been provided to them or to persons who are close to them. The positive aspect of such consumer perspectives is that they have the potential to provide to members of the community an opportunity to make informed decisions about the identity of professionals whom they consult, as well as about the skills and areas of expertise they make available.

A less positive aspect of online evaluation is that it can provide a forum for keyboard warriors (Douglas, 2018) — the disgruntled, the anti-professional (Fish, 1985-1986) and the vindictive. Expostulations abound on the Internet which weaponise social media, calumnying lawyers, doctors, dentists and other professionals. Unwarranted excoriations of professionalism, though, have the potential to cause significant mental harm, to damage reputations, engender anxiety about doctors' professionalism and to impact adversely upon professional practice, thereby generating measurable pecuniary losses. The issue that arises for professionals is whether they can or should engage in litigation against their clients/patients to secure redress and to bring to an end what may be a sequence of attacks upon their professional reputation.

This article reflects upon the emergence of a variety of legal actions, including defamation actions and applications for injunctive relief as means of inhibiting publishers' publication of unreasonable ratings of practitioners' professionalism and vindicating professionals' reputation for online attacks upon their professionalism.

\section{Online Rating of Professionals}

The rating of lawyers, accountants, health practitioners and others is gathering momentum as a means of consumer empowerment. For lawyers, there has been a proliferation of such sites, including Judge your Lawyer

(https://www.judgeyourlawyer.com.au), Avvo (https://www.avvo.com), Law

Choice (http://www.lawchoice.com.au/about/rate-a-lawyer), Go to Court

(https://www.gotocourt.com.au/rank-your-lawyer/), Law Twenty One

(https://www.gotocourt.com.au/rank-your-lawyer/)

(https://www.law21.ca/2008/04/client-based-lawyer-ratings/), My Case

(https://www.mycase.com/blog/2018/06/new-word-mouth-lawyer-ratings-revie

ws/), and Lawyerratingz (see "Patients Who Post Negative Comments about Healthcare Experiences on Social Media Review Sites are Being Sued by Physicians and Hospitals' Clinical Laboratories Might be Similarly Vulnerable to Being Drawn into Lawsuits", 2018). Such ratings systems, including their potential to incorporate client input are the subject of differing perspectives (Godfrey, 2014). Similarly, there are many rating sites for medical practitioners and dentists, including rateMDs (https://www.ratemds.com/vic/melbourne/), Whitecoat (https://www.whitecoat.com.au), Healthgrades (https://www.healthgrades.com), Zocdoc (https://www.zocdoc.com) and Yelp (https://www.yelp.com;) (O’Donnell \& Altucker, 2018; Miranda, 2016). At first such sites were controversial, although they were promoted by consumer groups and patient advocates (Van Der Wey- 
den, 2010; McCredie, 2011). A decade later they continue to be controversial (Bird, 2018; Kelly, 2016; Bravery, 2016). There are four business models for such sites:

(1) Private or nonprofit sites that provide information at no cost to patients. These range from the various professional boards that certify doctors to those that are advertising-based or charge fees to the doctors, other professionals or facilities to be listed.

(2) Private ownership sites that charge a fee to patients to access this information.

(3) Insurance company sites. Several health insurance organizations have built, or are in the process of building, doctor reference sites for their insurance customers to use. Some are hiring companies that rate other things to build these databases for them.

(4) Government sites provide information about the doctors licensed in their states (Torrey, 2020).

In Australia the Royal College of General Practitioners (2014) has contended that most medical practitioners find physician rating websites (PRWs) fundamentally flawed:

- How can a handful of ratings properly represent an appropriate assessment of a medical practitioner, who may see several hundred patients each month and many thousands over a career?

- The anonymity means there is generally no ability to identify the person who has posted the rating, is it a patient, a person who has a grudge against them or even a colleague who is 'in competition' with them?

- Is this an appropriate method of assessing a practitioner's skills as a doctor? It urged avoidance of self-posting of favourable reviews or orchestrating of patients to post such reviews.

Significantly, a 2016 review of commercial physician-rating websites found them to have "significant limitations ... Search mechanisms are cumbersome and reviews scarce. The number of physician reviews online appears to be increasing ... However, the increase in number of reviews we observed was not a meaningful most physicians in 2016 still had no more than one review on any site" (Lagu, Matayer, Moran, et al. 2017). Similarly, a 2018 review of the quality of patient rating websites (PRWs) assessed them as "mediocre" in quality:

The vast majority attained less than half of the maximum score (between 15-22 points), whereas the highest quality website attained 29 out of 47 points. Additional information such as surgeon volume or physician notification when the profile goes online were absent in almost 95\% (6/143) of all websites. Furthermore, only a quarter of websites contained physicians' replies to reviews, even though health care consumers report physician feedback to be crucial (Rothenfluh \& Schulz' 2018).

A 2019 Swiss study (McLennan, 2019) made a comparable point, suggesting 
that the situation had not changed significantly over the previous five years:

Google has substantially more ratings than the 3 dedicated PRWs in Switzerland over the past 2 and a half years. Overall, this study indicates that Swiss PRWs are not yet a reliable source of unbiased information regarding patient experiences and satisfaction with Swiss physicians; many selected physicians were unable to be identified, only a few physicians had been rated, and the rating posted were overwhelmingly positive.

Nonetheless, there is a sound argument, at least in principle, that patient online reviews ("PORs") published online can be both helpful to other patients and a salutary form of feedback for practitioners (Hong, Liang, \& Radcliff, 2018). They can also be empowering for patients in the sense of giving them a voice that they can expect will be listened to by their doctors (Hao \& Zhang, 2016). However, whether the cloud of patient experience can usefully be harnessed to detect health service quality reliably is doubtful as yet (Greaves, Ramirez-Cano, Millett, et al, 2013). The risk with such reviews provided by clients/patients is that they may be less than objective and factual and for reasons personal to the author may stray into a virulent critique of the practitioner's professionalism (Lyons, 2018). There can be many reasons for this, ranging from mental illness, disappointment about outcome, antagonism toward persons perceived as elite professionals, to outright vindictiveness.

Traditionally professionals have been reserved in their preparedness to take legal action against their clients/patients, accepting the burden of disappointment as one of the concomitants of the provision of services, and observing the exhortation to refrain from doing harm to their clients/patients (non-maleficence). Others simply accept that websites containing adverse, as well as positive, feedback are part of the contemporary doctor-patient ecosystem (Webster, 2018) and that taking action may neither be realistic nor constructive (Lyons, 2018). In addition, there is some evidence that prospective patients reading such reviews do not access what they read uncritically and that information attributes, such as review style and review number, have an impact on the evaluation of the review and on the patient's attitude toward the rated practitioner (Grabner-Krauter \& Waigunby, 2015).

However, the ubiquity and accessibility of forums in which there is the potential for uncensored vituperation to be published appears to be starting to erode these inhibitions.

\section{Identifying the Defendant}

A significant logistical problem for professionals aggrieved about the content of a publication is ascertainment of the identity of the author of the offending publication: in online publications authors of reviews often provide their feedback anonymously or utilising a false identity. In many jurisdictions the facility of pre-litigation discovery exists in principle to provide a remedy for such information deficits. In essence it can render the authors of evaluations of physician 
performance accountable by stripping them of their anonymity.

In Kabbage v Google LLC (2020) a breakthrough in terms of dealing with the anonymity of online reviewers was achieved. A prospective plaintiff in a defamation action was a dental surgeon based in Victoria. He relied on the Internet to attract customers across Australia. An unknown person posted on Google what he asserted was a defamatory review. Dr. Kabbage, the plaintiff, took action against Google, asserting that he was entitled to identifying information from Google about the reviewer, and contending that he met the statutory preconditions for such an order, namely that:

(a) there may be a right for the prospective applicant to obtain relief against the prospective respondent; and

(b) the prospective applicant is unable, notwithstanding having made reasonable inquiries and taken any other steps reasonably required in the circumstances, to ascertain the description of the prospective respondent; and (c) another person, the respondent to the application for preliminary discover, knows or is likely to know that description, or has or is likely to have, or has had was likely to have had, control of a document that would help ascertain that description.(Federal Court of Australia Rules 2011 (Cth), rule 7.22(1).

Murphy J of the Federal Court of Australia was satisfied that Dr Kabbage had satisfied the prerequisites and ordered Google to provide identifying information about the prospective defendant (CBsm23), including by providing:

(a) the subscriber information for CBsm23's account;

(b) the name of the users of that account;

(c) the IP address or addresses and associated information relating to that account;

(d) any phone numbers associated with that account;

(e) any location metadata associated with that account; and

(f) any other Google accounts including their full name and email address and identifying details which may have originated from the same IP address during a similar time period to when CBsm 23's account was accessed to post the offending Google review.

The decision constitutes a significant precedent. (see Moblisa v Doe, 2007) It undermines a key mechanism by which persons publishing material on reviewer websites may seek to hide behind their anonymity. It is a key litigation step in rendering them amenable to orthodox defamation actions.

\section{Lawyers Suing Their Clients}

Two decisions, the first in the United States, the second in Australia, are examples of a preparedness on the part of lawyers to consider legal recourse against disparaging clients.

In Blake v Guistibelli, PA (2016) the Florida District Court of Appeal upheld 
an award for damages for an attorney against her client. An attorney, Ann-Marie Giustibelli, represented Copia Blake in a dissolution of marriage proceeding against her husband Peter Birzon. In the aftermath of her representation of Ms Blake, Ms Blake and Mr Birzon posted Internet reviews containing aggrievements about the competence, integrity and honesty of their legal representation. Both Ms Blake and Mr Birzon admitted to posting the reviews on various Internet sites and admitted that Ms Giustibelli had not in fact charged four times more than what was quoted in the fee agreement: \$US300 per hour. At first instance the Florida District Court entered judgment in favour of Ms Giustibelli and awarded punitive damages of $\$$ US350,000. Ms Blake and Mr Birzon appealed, contending that their reviews constituted statements of opinion and thus were protected by the First Amendment and were not actionable as defamation. Their argument was emphatically rejected, with the Florida District Court of Appeal applying the Supreme Court formulation of defamation in Gertz $V$ Welch, Inc (1974):

[A] publication is libelous per se, or actionable per se, if, when considered alone without innuendo: (1) it charges that a person has committed an infamous crime; (2) it charges a person with having an infectious disease; (3) it tends to subject one to hatred, distrust, ridicule, contempt, or disgrace; or

(4) it tends to injure one in his trade or profession.

The appellate court affirmed the first instance decision.

In Cheng $v$ Lok (2020) Judge Bochner, a Master of the South Australian Supreme Court, awarded damages for the publication of defamatory material on a website by the name of Google My Business. The plaintiff was a Chinese-born South Australian lawyer in respect of whom the following review was published in English and Chinese:

\section{Re Gordon Cheng Barristers \& Solicitors \\ of level 1/186 Pultney Street, Adelaide SA \\ Isabel Lok}

Stay clear of this place! Gordon brings shame to all lawyers and is infamous for his lack of professionalism amongst the law society in Adelaide. He is only concerned about how to get most of your money by giving you false and misleading advices, and convincing you to go to court when it is clear that he doesn't have a case to win

After being served with a concerns notice, Ms Lok changed her first name and thereafter published a further review in her father's name, asserting Mr Cheng to be a "Bad Lawyer? Not at all reliable." Various communications then took place between Mr Cheng and Ms Lok in the course of which it emerged that Ms Lok had never been a client of Mr Cheng. Ms Lok did not defend the defamation action.

Mr Cheng asserted that the reputation of his business was harmed by the postings and that his personal reputation had been deleteriously affected as well. 
Judge Bochner accepted that "the publication of the review, and the consequent loss of business and need to retrench staff has caused the plaintiff great anxiety and distress" (Cheng V Lok, 2020). Mr. Cheng had been diagnosed with depression and prescribed medication for his symptoms. Judge Bochner noted the ease with which reviews on the Internet can be (and often are) republished and the fact that in a period of two months the review in question was viewed more than 1500 times, in spite of the fact that this was more than six months after the initial publication. Judge Bochnor was concerned to ensure that the general damages he awarded "be sufficient to signal the public vindication of [his] reputation." Cheng v Lok, 2020, at [57], applying Blue J in Duffy v Google Inc. (No. 2) 2015) $\mathrm{Mr}$ Cheng was awarded general damages of $\$ A 100,000$, aggravated damages of $\$ A 100,000$, damages for past economic loss of $\$ A 300,000$, damages for future economic loss of $\$ A 100,000$ and damages for loss of goodwill of $\$ A 150,000$, a total of $\$ A 750,000$.

\section{Health Practitioners Suing for Defamation}

German Case Law. In 2018 Germany's highest civil court ordered an online medical portal, Jameda, to delete website feedback against a dermatologist that had been published against her wishes. She complained that her right to privacy had been violated and that the practices of Jameda were unfair. The site contained information about over 750,000 German doctors, including "grades" from one to six given by patients who were permitted to be anonymous. Germany's Federal Court of Justice (BGH) held that the portal had failed to maintain the required neutrality, taking into account that Jameda offered special benefits to doctors who took out paid advertisements on the webpage, a practice that the lawyers for the dermatologist described as "protection money coercion". In addition, doctors who paid for Jameda services were given web pages free from links to competitors ("German Doctor Wins Right to Remove Name from Rating Website”, 2018).

In turn this prompted further litigation against Jameda in 2019 which resulted in a decision by the Munich District Court (the Landgericht München I) requiring the deletion of doctors' profiles in certain circumstances. Three doctors had demanded that their profiles, which again had been created without their consent, be removed from the site. The court did not find it illegitimate for profiles to be created without consent, though, finding that "the Jameda-operated medical assessment portal fulfils a socially acceptable function that is fundamentally approved by the legal system", as long as Jameda "maintains its position as a neutral information mediator". However, it reiterated that it should give its paying customers "no hidden advantages over non-paying base customers": the base customers admitted without their consent should not be used as an "advertising platform" for premium customers (see "Judgment: Jameda Has to Delete Doctors Profiles under Certain Circumstances", 2019).

Both German decisions are likely to constitute a significant precedent for the 
practices of commercial European doctor rating websites.

English Case Law. In Charakida v Jackson (2019) Warby J of the High Court of England and Wales heard and determined an application for damages for libel and an injunction to prevent repetition. The claimant was a dermatologist who was aggrieved about a blog entitled "Worst Liposuction Ever" in which he figured as the surgeon alleged to be responsible for an adverse outcome for his patient. Warby J accepted the allegations that the blog contained the following imputations:

(1) The Defendant was subjected to a burning pain during the Vaser Liposuction.

(2) The Vaser Liposuction was conducted in a manner which rendered it intolerably painful to the Defendant.

(3) The Vaser Liposuction was conducted in inappropriate, unprofessional, backroom premises.

(4) The Defendant was burnt during the Vaser Liposuction.

(5) The Vaser Liposuction was performed roughly in a manner which has left the Defendant with a poor cosmetic outcome.

(6) The Vaser Liposuction was performed without anaesthetic and as a consequence, the Defendant was subjected to exquisite or excessive pain.

(7) The Vaser Liposuction was performed without anaesthetic and as a consequence, the Defendant was subjected to exquisite or excessive pain.

(8) The Vaser Liposuction has been performed inadequately and substandardly leaving the Defendant with an inadequate cosmetic result.

Ultimately the claim was not defended and Warby J granted the injunction sought, awarded damages in the sum of $£ U K 6000$ under a summary disposal, and costs, commenting: "I consider this to be an appropriate sum by way of general damages for allegations of the kind I have identified, levelled at a Consultant Dermatologist whom I must presume to be of good character and reputation, which have been read by several people online, and have resulted in "a number" of cancellations" (Charakida v Jackson, 2019, at [37]).

The precedent value of the Charakida decision is modest, but it is a further warning about unfair and unjustified assertions published online.

Canadian Decisions. In a series of Canadian judgments actions brought for defamation by medical practitioners have been found established and damages have been awarded.

In Sagman $v$ Davis (2014), for instance, Morgan J of the Ontario Superior Court of Justice heard an action for defamation brought by two plaintiffs who were successful medical practitioners, the first a psychiatrist and medical technology entrepreneur developing advanced nanomedicine and biotechnology innovations, and the second a vice-president of a major pharmaceutical company, Eli Lilly Canada Inc.

The plaintiffs were the subject of Internet postings by entities owned and controlled by the defendants. The defendants had been aggrieved in relation to liti- 
gation previously brought by the plaintiffs in respect of a failure by one of the defendants to complete a condominium purchase. The defendants had previously taken an action against one of the brothers with the College of Physicians and Surgeons in which he sought revocation of the practitioner's licence to practise medicine. After investigation the College determined that the complaint did not warrant further investigation or action.

Morgan J found that the defendants had published a wide variety of false allegations directed toward the plaintiffs' alleged financial dealings and had also alleged that they could not be trusted as doctors. As a result of the posting on a medical website the first plaintiff's ranking was downgraded to "Very Bad". Morgan J acknowledged that the two websites were removed from the Internet but concluded that:

it is impossible to erase the damage that they caused when they were published. The false statements contained in those websites tended to "lower [the Plaintiffs] in the estimation of right-thinking members of society generally and in particular to cause [them] to be regarded with feelings of hatred, contempt, ridicule, fear, dislike, or disesteem": Colour Your World $v$ Canadian Broadcasting Corporation, 1998 CanLII 1983 (ON CA), [1998] OJ No 510, paras 14-15 (SCJ). The affidavit evidence from the Plaintiffs establishes that the statements in the websites accusing them of criminal offences and calling them untrustworthy doctors caused patients and colleagues alike to perceive them under a cloud of suspicion and to treat them as persons with questionable professional reputations (Sagman $v$ Davis 2014: at [16]).

He observed that:

The defamatory statements in the instant case were published in a medium notorious for its ability to spread falsehoods far and wide. Scholars and courts alike have noted that not only are web postings "communicated through a medium more pervasive than print, and for this reason they have tremendous power to harm reputation ... [but] [t] he extraordinary capacity of the Internet to replicate almost endlessly any defamatory message lends credence to the notion that 'the truth rarely catches up with a lie"': Lyrissa Barnett Lidsky, "Silencing John Doe: Defamation and Discourse in Cyberspace” (2000) 49 Duke LJ 855, at 862-865 (Sagman v Davis 2014: at [23]).

He found the defamation proved and order the defendants to pay the plaintiffs $\$ C 300,000$ and $\$ C 50,000$ in punitive damages, as well as a substantial sum in costs.

In Zoutman v Graham (2019) Mew J of the Ontario Supreme Court of Justice heard an action for defamation against RateMDs.com and the brother of a former patient of Dr Zoutman, a specialist in infectious diseases and Professor Emeritus in the Faculty of Health Sciences at Queen's University, Kingston. By the time of the hearing, the action against RateMDs.com had been resolved. 
The defendant's brother had died as a result of post-operative complications following an operation. A lawsuit alleging negligence was initiated by the deceased man's family and Dr Zoutman was called by the defence as an expert witness at the trial. The action failed but the defendant, who was present when Dr Goutman gave evidence, posted a rating on Dr Goutman's RateMDs.com profile, alleging him to be arrogant, obstinate, condescending ignorant, dangerous and delusional.

Dr Goutman claimed multiple postings by the brother of the deceased man to be defamatory, contending that the defendant masqueraded as a patient by purporting to rate Dr Zoutman's services as a physician; the defendant criticised Dr Zoutman by making false and derogatory statements undermining the practitioner's competence and trustworthiness as a physician; and the defendant mischaracterised Dr Zoutman's evidence to portray him falsely as posing a danger to patients.

Mew J noted that no evidence had been placed before the court about the extent to which persons other than Dr Zoutman and his lawyers had viewed the impugned postings or of any loss of patients or of professional standing on the part of Dr Zoutman. However, Dr Zoutman pointed to the prominence of his rating of RateMDs.com (although by the time of trial it had been taken down), evidence about the extent to which patients were utilising such rating sites, and contended that he was living under the constant apprehension that a new posting from the deceased man's brother would appear. He claimed to feel distressed by the need to monitor RateMDs.com and other online reviewing services constantly for new postings from the deceased man's brother.

Mew J rejected the defendant's claim to having authored only two of the twelve postings and expressed no hesitation in "concluding that the language used to describe Dr Zoutman in the postings would lower the reputation of a doctor in the estimation of right thinking members in the community. The comments posted by Mr Graham are derogatory and degrading to Dr Zoutman, both personally and professionally. Some of the postings go to the very core of Dr. Zoutman's integrity. He is accused of "reckless behaviour", "turns to bullying", and "epitomizes all that is wrong with the health care system in this country'." (Zoutman v Graham (2019, at [70]-[71]) He was satisfied that publication had been proved and that the defence of fair comment could not be made out in the absence of the defendant being a patient of Dr Zoutman, although some of his statements made it appear that he was. He determined that there was no public interest in the comments that the deceased man's brother had published. He pointedly concluded that that although it was understandable that the brother of the deceased was angry and did not accept the verdict of the jury, associating the verdict that was disappointing for him with the evidence of Dr Zoutman, "none of that justifies or excuses Mr Graham's malicious comments. His asserted belief in his comments did not bear up under cross-examination. I have no hesitation in concluding that he acted out of malice." Zoutman v Gra- 
$\operatorname{ham}(2019$, at [108]-[109]).

In light of the failure by Dr Zoutman to adduce evidence about the extent of harm to his reputation or of specific detriments to his practice arising from the defamatory publications, Mew J assessed general damages at a modest level. He awarded \$C25,000 and, in addition, \$C25,000 in aggravated damages. He issued injunctions to prevent recurrence of the defamatory statements and signalled an intention to order the deceased man's brother to pay the costs of the proceedings.

In Pathak $v$ Shapira (2019) Kumar Pathak, a professor at the University of Manitoba and a surgeon at Cancer Care Manitoba and the Health Sciences Centre and St Boniface Hospital, sought injunctions from the Court of Queen's Bench in Manitoba to prohibit a person from directly or indirectly defaming, disparaging or otherwise damaging his business, reputation and goodwill. McCawley J found that Professor Pathak had been the victim of a campaign of intimidation, harassment, defamation, blackmail and extortion, which had extended to threats of imprisonment and even unfounded allegations of physical and sexual abuse of minors asserted to have been perpetrated by Professor Pathak. He concluded that the campaign against Professor Pathak had taken a serious toll on its victim with Professor Pathak being diagnosed with "situational depression" and having missed a month's work from his work as an oncologist. He concluded that the allegations made against him were "clearly designed to cause irreparable damage to Dr Pathak's reputation, the trust others repose in him and have affected his medical practice" Pathak v Shapira (2019, at [6]).

McCawley J could not identify the motive of the defendant but took into account that at no time had he made any retraction of his false statements. He ordered general damages of $\$ C 200,000$, aggravated damages of $\$ C 100,000$ and punitive damages of $\$ C 50,000$, as well as costs, along with making a series of injunctive orders to prevent continuation of the injurious conduct.

This series of Canadian decisions constitutes an evolving body of case law providing support for health practitioners' actions for defamation and injunctive relief against unreasonable online publications.

Australian Authority. Similarly, in New South Wales, Australia, in 2017 and 2019 there were significant decisions by the Supreme Court, granting defamation relief to doctors who claimed that they had been defamed in the professional context by patients or commentators.

The first was Al Muderis v Duncan (No 3) (2017; see also Freckelton, 2017) in which Rothman J of the New South Wales Supreme Court heard a defamation action brought by Associate Professor Al Muderis, a high-profile Iraq-born, orthopaedic specialist. Dr Al Muderis had undertaken a hip arthroscopy on a patient who alleged that he had suffered complications from the operation. However, what he asserted did not withstand any critical scrutiny. The patient then directly and indirectly engaged in a series of publications on the Internet, including a Facebook page and on Youtube, vilifying Dr Al Muderis.

$\mathrm{Dr} \mathrm{Al}$ Muderis sued alleging he was the victim of multiple imputations on his 
reputation as a surgeon including that it had been suggested by the patient that Dr Al Muderis was grossly negligent; deserved to be found guilty of misconduct by the Medical Board; should be criminally charged; had mutilated the patient's reproductive nerves, destroying his sex life; was unethical, disgraceful and had no regard for human life; was a butcher and a bully; and had created false documents to cover up his errors. The evidence adduced before Rothman J satisfied him that there had been no negligence or wrongdoing on the part of $\mathrm{Dr} \mathrm{Al}$ Muderis and in fact that that the hip arthroscopy he had performed had been successful and caused no further injury (Al Muderis v Duncan (No 3), 2017, at [20]).

The publications by the patient were repeated and included threats to kill $\mathrm{Dr}$ Al Muderis. They were also directed toward his wife and children. Rothman J took into account the fact that there had been no apology or correction of the imputations against Dr Al Muderis. He also noted the "grapevine effect" of what had been published but concluded that the extent of the publication and its republication by grapevine could not be established. He classified the reputation of Dr Al Muderis as "extremely high or at the highest possible level" (Al Muderis V Duncan (No 3), 2017, at [116] and the level of hurt feelings and damage to his reputation as "extremely high, and, probably, at the highest level". He found aggravated damages to be justified and ordered damages on two different categories of publication at $\$ A 320,000$ and $\$ A 160,000$ respectively. He also issued injunctions to prevent further such publications.

In Tavakoli v Imisides (No 4) (2019) Rothman J heard another action for defamation (as well as injurious falsehood), on this occasion brought by Dr Tavakoli, an Iranian-born plastic and reconstructive surgeon, arising from statements made by a former patient and her husband. The action arose from Google reviews published by a patient that alleged that Dr. Tavakoli charged her for a buccal fat procedure he performed on her and that he acted improperly and incompetently in relation to the procedure, and then a further Google review published by the patient in contravention of a court order; and a telephone call by the patient's husband to Dr. Tavakoli.

The claim against the patient related to a review from which it was said that the reasonable reader would identify that:

(1) Dr. Tavakoli was an incompetent plastic surgeon, in that a rhinoplasty he had performed had been unsuccessful;

(2) Dr. Tavakoli was cruel in his dealings as a doctor, in that he did not provide assistance to his patients who were unhappy with their results post-surgery; and

(3) Dr. Tavakoli was a bully in that he intimidated patients who raise a reasonable complaint about his work by using his lawyers to threaten them.

The evidence adduced before Rothman J established that Dr Tavakoli performed three procedures on the patient in question, although the nature of the procedures that he undertook were the subject of contest. The conduct of $\mathrm{Dr}$ 
Tavakoli was the subject of reviews by the patient and her husband.

A few days after the first review was published showed that the rate of visitors to the site had dropped by $23.61 \%$ since the publication. Injunctions were obtained by Dr Tavakoli but the patient then published a second Google review. When a request was made that she take it down, she refused robustly and offensively.

Rothman J found that the patient knew that her statement in the first Google review, the statement made to her husband as to the non-performance of the operation, and the second Google review statements were untrue. The circumstances of the case, particularly the repeated publication of imputations and the threats to continue to repeat defamatory imputations, satisfied Rothman J that it was a clear case for permanent injunctions.

On the issue of the damages for defamation Rothman J had regard to the fact that the harm suffered by Dr Tavakoli was a combination of hurt to his feelings and damage to his reputation, including his business reputation, upon which he depended for his commercial viability. Rothman J concluded that the patient had published the material in order to punish Dr Tavakoli, knowing what she was publishing was false, she had refused to apologise, at first she declined to withdraw the offending publication from the Internet and then she published a second defamatory publication, only withdrawing it upon being urged strongly to do so. By contrast, the evidence before the court was that Dr Tavakoli enjoyed an exemplary reputation among his patients, within his social circle and in the profession. Rothman J was satisfied that aggravated damages were appropriate and awarded the sum of $\$ A 530,000$.

The Australian decisions are consistent with the German, English and Canadian case law and are part of an evolving international body of law which has provided recourse to health practitioners who have been found to have been victimised by online publications.

\section{Conclusion}

The Internet can pose temptations to the aggrieved to suspend restraint and publish impulsively the product of bile, frustration, disappointment and distress. Otherwise law-abiding and responsible persons can transmogrify into keyboard warriors, prepared to write on online forums assertions and accounts which otherwise they would not be prepared to ventilate publicly. However, such publications have the potential to have measurably significant effects that are detrimental to the reputation and commercial status of the person who are their subject. They can also cause considerable personal harm, even amounting to psychiatric pathology.

In the cases from Germany, England, Canada and Australia to which reference has been made in this article the courts have been prepared to find allegations of defamation proved and to order reparative action, often including damages against the tortfeasors. The sums have varied depending upon what has been proved. On some occasions too injunctive relief has been given by courts in 
an attempt to inhibit the publication of further defamatory statements. While actions for defamation can be limited in their efficacy when defendants have no assets or are intractably obdurate in their conduct, injunctive orders carry the potential for powerfully coercive enforcement and thus can be effective.

It is apparent from the cases discussed in this article that the motives of those who defame professionals can vary widely. However, it is significant that websites and commercial organisations hosting or making a profit from such publications have also been held accountable. In each instance where defamation of professionals has been proved, the reality and the rhetoric of the courts have incorporated an attempt to vindicate the reputation of the practitioner and to restore them to the status of good standing which they enjoyed prior to the defamatory publications. Another agenda in such cases has been the attempt by the courts to inhibit the defendant from continuing their harmful conduct. While most professionals will be hesitant to pursue litigation against their clients/patients, persons associated with them, or individuals otherwise assailing their professional reputation, it is apparent that there is preparedness on the part of some practitioners to draw a line in the sand in relation to false and unreasonable online publications and to seek recourse in the courts. This is in part to vindicate their reputation in the relevant marketplace but also to protect themselves against the harms occasioned by the currency of false allegations. The success of such actions in a number of countries is likely to lead to an increase in the incidence of legal actions brought by professionals against their clients/patients and persons closely associated with them who are responsible for false accounts and accusations that are published online.

\section{Conflicts of Interest}

The author declares no conflicts of interest regarding the publication of this paper.

\section{References}

Bird, S. (2018). How Does My Doctor Rate? MDA National. https://www.mdanational.com.au/advice-and-support/library/articles-and-case-studies 12018/02/how-does-my-doctor-rate

Bravery, B. (2016). Rate-My-Doctor Technology Is Not What the Doctor Ordered. Huffington Post.

https://www.huffingtonpost.com.au/ben-bravery/rate-my-doctor-technology-is-not-w hat-the-doctor-ordered a 21605945/

Douglas, M. (2018). Before You Write that Scathing Review Online, Beware of Defamation. The Conversation.

http://theconversation.com/before-you-write-that-scathing-online-review-beware-of-d efamation-92595

Fish, S. (1985-1986). Anti-Professionalism. Cardozo Law Review, 645.

Freckelton, I. (2017). Doctors Suing Patients: Wrestling with Doing No Harm. Journal of Law and Medicine, 24, 749-755. 
German Doctor Wins Right to Remove Name from Rating Website (2018). DW.com. https://www.dw.com/en/german-doctor-wins-right-to-remove-name-from-rating-web site/a-42654605

Godfrey, P. (2014). Controversial Lawyer Rating to Hit Australia. Australian Lawyer. https://www.thelawyermag.com/au/news/general/controversial-lawyer-ratings-to-hit-a ustralia/196787

Grabner-Krauter, S., \& Waigunby, M. K. J. (2015). Insights into the Impact of Online Physician Reviews on Patients' Decision Making: Randomized Experiment. Journal of Medical Internet Research, 17, e93.

https://www.ncbi.nlm.nih.gov/pmc/articles/PMC4408377/ https://doi.org/10.2196/jmir.3991

Greaves, F., Ramirez-Cano, D., Millett, C. et al. (2013). Harnessing the Cloud of Patient Experience: Using-Social Media to Detect Poor Quality Healthcare. BMJ Quality \& Safety, 22, 251-255. https://doi.org/10.1136/bmiqs-2012-001527

Hao, H., \& Zhang, Z. (2016). The Voice of Chinese Health Consumers: A Text Mining Approach to Web-Based Physician Reviews. Journal of Medical Internet Research, 18, e108. https://www.jmir.org/2016/5/e108/

https://doi.org/10.2196/jmir.4430

Hong, A., Liang, C., \& Radcliff, T. A. (2018). What Do Patients Say About Doctors Online? A Systematic Review of Studies on Patient Online Reviews. Journal of Medical Internet Research, 21, e12521. https://www.jmir.org/2019/4/e12521/ https://doi.org/10.2196/preprints.12521

Judgment (2019). Jameda Has to Delete Doctors Profiles Under Certain Circumstances. Newsrnd.

https://newsrnd.com/tech/2019-12-06--judgment--jameda-has-to-delete-doctors-profil es-under-certain-circumstances-.BkWMtJ aB.html

Kelly, C. (2016). Whitecoat-Rating Your Doctor Online. Hospital Health. https://www.hospitalhealth.com.au/content/aged-allied-health/article/whitecoat-rating -your-doctor-online-469545237\#axzz6ECCM1CAZ

Lagu, T., Metayer, K., \& Moran, M. (2017). Website Characteristics and Physician Reviews on Commercial Physician-Rating Websites. Journal of the American Medical Association, 317, 766-768. https://doi.org/10.1001/jama.2016.18553

Lyons, A. (2018). Can They Really Say That? GPs and Online Reviews. News GP. https://www1.racgp.org.au/newsgp/professional/can-they-really-say-that-gps-and-onli ne-reviews

McCredie, J. (2011). “A Scathing Review” (14 November 2011) MJA Insight.

McLennan, S. (2019). Quantitative Ratings and Narrative Comments on Swiss Physician Rating Websites: Frequency Analysis. Journal of Medical Internet Research, 21, e13816. https://europepmc.org/article/PMC/6688440 https://doi.org/10.2196/13816

Miranda, L. (2016). Yelp Warning: This Dentist Might Sue You for Posting a Negative Review. BuzzFeed News.

https://www.buzzfeednews.com/article/leticiamiranda/yelp-warns-dentist-may-sue

O’Donnell, J., \& Altucker, K. (2018). Doctors, Hospitals Sue Patients Who Post Negative Comments, Reviews on Social Media.

https://www.usatoday.com/story/news/politics/2018/07/18/doctors-hospitals-sue-patie nts-posting-negative-online-comments/763981002/

Patients Who Post Negative Comments about Healthcare Experiences on Social Media 
Review Sites Are Being Sued by Physicians and Hospitals' Clinical Laboratories Might be Similarly Vulnerable to Being Drawn into Lawsuits (2018). Dark Daily.

https://www.darkdaily.com/patients-who-post-negative-comments-about-healthcare-e xpe-

riences-on-social-media-review-sites-are-being-sued-by-physicians-and-hospitals-clini cal-laboratories-might-be-similarly-vulnerable-to-being-d/

Rothenfluh, F., \& Schulz, P. J. (2018). Content, Quality, and Assessment Tools of Physician-Rating Websites in 12 Countries: Quantitative Analysis. Journal of Medical Internet Research, 20, e212. https://www.jmir.org/2018/6/e212/

https://doi.org/10.2196/jmir.9105

Royal Australian College of General Practitioners (2014). Patients' Use of Social Media: e-Rating of Doctors. Australian Family Physician, 43, 885-886.

https://www.racgp.org.au/afp/2014/december/patients'-use-of-social-media-e-rating-of -doctors/

Torrey, T. (2020). What You Can Learn from Doctors' Rating Sites. Very Well Health. https://www.verywellhealth.com/doctor-ratings-and-rankings-sites-criteria-and-uses-2 $\underline{614989}$

Van Der Weyden, M. (2010). eRating Doctors. Medical Journal of Australia, 192, 425. https://doi.org/10.5694/j.1326-5377.2010.tb03576.x

Webster, P. (2018). Online Ratings for Doctors Are Flawed, but "Not Going Anywhere". Canadian Medical Association Journal, 190, E305. https://www.cmaj.ca/content/190/10/E305 https://doi.org/10.1503/cmaj.109-5565

\section{Appendix}

\section{Case References}

Al Muderis v Duncan (No 3) [2017] NSWSC 726.

Blake v Guistibelli, PA, 182 So 3d 881 (Fla 4th DCA, 2016).

Charakida v Jackson [2019] 4 WLR 66; [2019] EWHC 858 (QB).

Cheng v Lok [2020] SASC 14.

Duffy v Google Inc (No. 2) [2015] SASC 206.

Gertz v Welch, Inc, 418 US 323 (1974).

Kabbage v Google LLC [2020] FCA 126.

Moblisa v Doe, 170 P 3d 712 (Ariz Ct App 2007).

Pathak v Shapira [2019] MBQB 73.

Sagman v Davis [2014] ONSC 4183.

Tavakoli v Imisides (No. 4) (2019) NSWSC 7.

Zoutman v Graham (2019) MBQB 73. 